\title{
USO Y ABUSO DEL CONCEPTO DE RESILIENCIA
}

\author{
Adriana Schiera
}

\begin{abstract}
RESUMEN
La resiliencia es un concepto que ayuda a comprender situaciones en que determinadas personas superan la adversidad. Premisa que permite ahondar en su contenido y limites para entender en su real dimensión, determinadas características humanas, en el marco de la Psicología y las ciencias humanas. El presente artículo cubre las relaciones psicológicas que se establece al abordar esta temática.
\end{abstract}

Palabras claves: Personas resilientes, impronta, experiencia adversa.

\begin{abstract}
The resiliencia is a concept that helps to understand situations in which certain persons overcome the adversity. Premise that allows to go deeply into his content and limits to deal with his royal dimension, certain human characteristics, with the frame of the Psychology and the human sciences. Present I articulate it he, covers the psychological relations that are established on having approached this subject matter.
\end{abstract}

Keywords: Persons resilientes, stamp, adverse experience.

\section{A MODO DE INTRODUCCIÓN}

Los profesionales de la salud mental somos buscadores incorregibles. Siempre hay alguna razón para querer extender los límites de nuestro saber. Sea en dirección longitudinal, transversal o en profundidad, buscamos puntualizar al máximo algún particular. A veces, intentamos ejercicios de vuelos existenciales para explorar allí, donde algo sugiere una promisoria revelación. También está el innegable afán de compartir nuestras reflexiones para que sean una gota más en el infinito espacio científico.

En esta oportunidad, el concepto de resiliencia aplicado a las ciencias humanas me lleva a considerarlo en relación a otro concepto, el de vulnerabilidad somática.

Siendo tan importantes en la actualidad, los desarrollos en el área de psicosomática, considero apropiada esta ocasión para tener en cuenta otro factor que disminuya el padecer de nuestros consultantes y nos acerque una accesible herramienta de observación e intervención, pero especialmente de prevención en nuestra actividad clínica. 


\section{LA CIRCULACIÓN DE TERMINOLOGÍA}

Nuestro tiempo nos enfrenta con la contundente diversidad y complejidad del fenómeno humano. Cuando la ciencia del hombre pretende describir dicho fenómeno, suele resultar de su quehacer, un recorte encorsetado que deja muchos aspectos fuera de la explicación posible. Además los refrescantes saberes de otras áreas, logran expresar lo que tal vez siempre supimos, pero que no requería de nuestra explicación, pues no alcanzaba la intensidad que llevaría a su recorte epistemológico, produciendo la diferencia que llevaría a la necesidad de conceptualizar.

También es la realidad quien nos hace preguntar por aquello que contradice nuestras hipótesis. Sabemos que una hipótesis es un ordenador de nuestro conocimiento. Si es confirmada, nos confirma a su vez. Pero no siempre esto ocurre, y es allí cuando el motor de la mente científica se pone en actividad, tentando otras afirmaciones que den cuenta del observable.

Ahora bien, una de las premisas de un profesional es que puede anticipar, prever el curso de los acontecimientos en virtud de los conocimientos acopiados. Para ejemplificarlo, es la base de la implementación de técnicas psicométricas, proyectivas o la aplicación de categorías diagnósticas.

Sin caer en obviedades, sabemos que en el terreno de las ciencias humanas, jugamos dentro de un marco bastante amplio a la hora de pronosticar, pero teniendo la mayor cantidad de factores posibles en consideración, tentamos derroteros y operamos de acuerdo a este criterio. De no ser así, estaríamos más del lado del arte que de la ciencia, aunque los psicólogos sabemos que nos desplazamos permanentemente sobre ambas cabalgaduras.

Pensando en términos de anticipación y previsión, nuestra época nos ofrece desafíos constantes.

La realidad suele superar a la ficción, las personas sucumben ante lo inesperado y sobreviven frente a lo inefable. Surge entonces la pregunta ¿cómo es esto posible?

Me refiero a las observaciones que contradicen nuestros pronósticos y nos dejan perplejos cuando algo que, debiendo conducir necesariamente a la muerte, la locura o en el mejor de los casos a una pésima calidad de vida, no lo hizo.

\section{COMENZAMOS A SISTEMATIZAR}

Será por eso que la terminología usada habitualmente en otras áreas, resulta de utilidad cuando ciertos temas de la conducta humana ocupan el primer plano de nuestro interés.

Así, el término resiliencia adquirió un estatus dentro de las ciencias humanas, y últimamente nos hemos ocupado de incorporarlo, adecuarlo y precisar sus alcances, como así también, los cuidados de una aplicación abusiva, o aún peor, una aplicación mal intencionada.

Para la metalurgia, la resiliencia es la capacidad que tienen los metales de contraerse, dilatarse y recuperar su estructura interna.

Para la ingeniería, es la capacidad de una viga de soportar peso sin quebrarse. Luego, en las ciencias humanas, usamos el término resiliencia para referirnos a un factor observado en ciertos individuos, que les permite afrontar, resistir y superar la adversidad con más recursos y mejores resultados que las mayorías de las personas. Estos sujetos que no 
responden a lo sostenido desde las hipótesis de la psicología, acerca de las respuestas humanas frente a circunstancias límites, han despertado el interés de los especialistas, tanto por el aspecto investigativo como por los usos benéficos en materia de prevención, que traería reconocer la dinámica de este factor en el desarrollo de una persona.

Resulta importante aclarar que al hablar de un factor, no se está definiendo un aspecto estático de la persona. Entendido en términos dinámicos, puede decirse que resiliencia es también la capacidad de potenciar los mecanismos que posee una persona para elaborar las circunstancias adversas que debe atravesar en su vida.

¿Es este un aspecto que sólo debe ser pensado en la subjetividad? Por cierto que no. Hay comunidades, que a lo largo de la historia demostraron tener recursos para sobrevivir a circunstancias que desbastaron a otros grupos humanos.

Resumiendo, prefiero circunscribir el presente trabajo a la definición del término resiliencia que sigue: recursos que desarrolla una persona, grupo o comunidad para tolerar y superar los efectos de la adversidad.

Enfocando ahora este tema, pragmáticamente, enumeraré algunas de las acciones concretas más evidentes y fundamentales que podemos observar en sujetos considerados resilientes.

1. Lograr objetivos a pesar de la situación. Al planificar una tarea, proyecto o llevar a cabo los pasos de una situación determinada, tenemos objetivos explícitos o no y también presuponemos las circunstancias en que esto será llevado a cabo. Si bien incluimos variables de ajuste, puede ocurrir que algo transforme las condiciones anticipadas. Es entonces cuando se podrá ver cómo se maneja cada persona y qué resulta de ello. Quienes pueden reencuadrar la situación favorablemente, quienes disponen de una actitud flexible y recursos creativos, logran sus objetivos sin sucumbir a las cuestiones contextuales adversas.

2. Mantenerse competente a pesar de la situación. Muchas personas pueden desarrollar sus habilidades en el marco de lo conocido. Pero hay quienes pueden mantener sus competencias intelectuales, manuales, etc., preservándoles de influencias negativas del entorno. La posibilidad de utilizar defensas yoicas como la disociación instrumental, la negación, la sublimación, les permite continuar donde otros abandonarían o se desesperanzarían. También se observa que pasa mucho mejor una situación de crisis, aquella persona que se mantiene activa en virtud de sus capacidades, preservándose así de los efectos que producen la frustración o la impotencia. Seguramente estará conciente de aquello que no puede modificar, aun deseándolo hacer, pero lo ayuda a "resistir" el seguir haciendo todo lo que puede.

3. Aquellos que superan situaciones pasadas. Las personas que pueden elaborar sus pérdidas, es decir, quienes tienen la capacidad de duelar, con todo lo que implica este proceso, también son consideradas resilientes. Se los ve reponerse luego de procesar las implicancias de lo que han perdido y pueden construir luego procurándose un futuro con mejor calidad de vida. No se quedan melancólicamente detenidos por el atravesamiento de la adversidad, evitando un destino de doble devastación.

Desde la observación y las inferencias que resultan de ella, los estudiosos de las personas resilientes coinciden en la enumeración de ciertos acontecimientos presentes en la historia de estos sujetos. Si bien son los mismos estilos relacionales que los psicólogos hemos 
reconocido y descrito con diferente terminología (holding para la escuela inglesa, importancia de la estimulación para las corrientes de la psicología del yo, desarrollo de una comunicación congruente para los desarrollos de los ecólogos de la mente), vale la pena encuadrarlos en esta oportunidad. Estos son:

1. Demostraciones físicas y verbales de afecto y cariño en los primeros cuatro años de vida.

2. Actitud de cuidado y amor por todos los semejantes, y especialmente de los encargados del cuidado y protección del niño.

3. Reconocimiento y atención a los logros y habilidades del niño.

4. Disponer de oportunidades para desarrollar destrezas.

5. Desarrollo de un marco de referencia ético-moral.

Deseo señalar que lo que precede puede parecer redundante, sino obvio, sin embargo, y como explicito hacia el final del presente trabajo, es muy complicado en el mundo que viven nuestras familias, con frecuencia excedidas por la realidad, llevar a cabo la función parental, aun sabiendo lo que es bueno y queriendo hacerlo. Además, en una sociedad atomizada es difícil sentir que los niños son responsabilidad de todos, y no sólo de sus padres como se cita en el segundo punto. El cuarto punto está estrechamente vinculado a cuestiones socioeconómicas, que no siempre toman en cuenta las opiniones de los especialistas en salud mental, llevando adelante políticas que permitan el adecuado progreso físico y emocional de los sectores jóvenes de la población.

El último punto, la importancia de un marco de referencia ético-moral, si bien es un aspecto implícito en todo individuo, grupo o sistema, está amenazado por fuertes tendencias que priorizan lo urgente, lo inmediato, antes que lo importante para la sobrevida de la especie humana. Si bien, soy plenamente conciente de lo limitado que resulta el abordaje psicológico para adentrarse o dar cuenta de este marco supraindividual, reafirmo, toda vez que se puede, su importancia para el sostenimiento de la subjetividad. En otro trabajo muestro su importancia y el peligro que conlleva darle un tratamiento superficial o tergiversado, ya no por las decisiones sociopolíticas, sino por los propios profesionales a la hora de desarrollar su labor ${ }^{1}$.

Finalmente, quiero resumir los principales aspectos que favorecen la aparición o el desarrollo del factor de resiliencia en un individuo, grupo o comunidad. Ellos se infieren de lo expuesto con anterioridad. Es decir, una persona que ha recibido en su crecimiento contención, cuidados, amor y enseñanzas en un marco estable y saludable los dispone o es capaz de incrementarlos.

- $\quad$ Autoestima.

- Capacidad de amar.

- Capacidad de cambiar.

- Capacidad de construir realidades diferentes.

- Capacidad de reencuadrar situaciones.

1 Credos y disfunción familiar ¿Otras violencias?, Conferencia, Lic. Adriana Schiera, Congreso Internacional de Psicología - Propuesta de una psicología para el futuro, UNMSM, Lima-Perú, octubre 2005. 
- Coherencia y congruencia.

- Competencias cognoscitivas.

- Confianza en sí mismo.

- $\quad$ Disponer de proyectos.

- Optimismo.

- Pertenencia a una red.

- $\quad$ Recursos creativos.

- Responsabilidad.

- $\quad$ Sentido del humor.

Visto en forma aislada, todos podríamos identificarnos con una buena cantidad de pautas del listado anterior, sin embargo, si estamos rescatando esta cualidad de unos pocos en el mundo, que logró concitar la atención de los estudiosos, es porque no resulta fácil ni frecuente disponer de ella. Entonces cabe la pregunta ¿a qué puede deberse no ser resiliente?

Hemos visto qué se considera factor de resiliencia, cómo detectarlo y qué lo favorece o lo desarrolla. Pero podríamos pensar este tema desde el enfoque opuesto.

¿Cuándo no se puede o es más difícil desarrollar este factor? ¿Qué hace que una persona no lo haya desarrollado o no pueda disponer de él cuando lo afecta la adversidad?

Si pensamos en el sujeto, es claro que aquellas personas que llamamos vulnerables somáticas, es decir, que han tenido una crianza deficitaria, que sufrieron estados de tensión intensa, privación o trauma temprano, al estar en situación de riesgo por determinadas exigencias del medio, enfrentarán estas situaciones, con menores recursos de procesamiento mental, comprometiendo su cuerpo (enfermedades, adicciones, accidentes) o sus vínculos afectivos y redes de pertenencia (estilo vincular asocial, violencia).

Pero también podemos pensar que una persona con un desarrollo promedio y una historia "suficientemente buena" puede colapsar ante determinados hechos impensados por injustificables.

Sabemos que las personas deben afrontar la muerte natural, es decir, la que indefectiblemente sobrevendrá al completarse el ciclo vital. La muerte por vejez, aun implicando el consabido duelo, es dentro de lo humano la más aceptable.

No podemos asimilar igual la muerte cuando hablamos de enfermedad, discapacidad, muerte prematura, o es la resultante de una catástrofe o accidente inevitable. En estos casos la persona reconoce su fragilidad, su impotencia, pero sabe que está frente a algo que no podría haber evitado.

Es diferente la situación de las muertes injustas e innecesarias (indefensión, asesinatos, guerras, intolerancia ideológica, xenofobia, etc.). El hombre no espera que la muerte llegue en la mano de otro hombre, mucho menos que sea injusta y peor aún, que quede impune. Soportar este tipo de situaciones requiere una capacidad extra en las conductas de afrontamiento y es precisamente a lo que aplico el término resiliencia, por lo que estoy en situación de reformular la primera definición, reemplazándola por la que sigue: 
Son los recursos que desarrolla una persona, grupo o comunidad, para tolerar y superar los efectos de la adversidad causada por hechos que superan la capacidad anticipatoria del sujeto, grupo o comunidad en especial cuando resulta, dicha adversidad, de la trasgresión a la norma primordial de la especie que es preservar la vida de sus miembros.

En este tipo de adversidad se ubica, especialmente, la muerte por causas injustas e innecesarias y que queda impune por falta de reconocimiento del daño infringido y ausencia de la reparación, por parte del marco social al que pertenece quien ha sufrido la pérdida o recibido el agravio.

\section{IMPORTANCIA Y LIIMITES}

Los especialistas en salud mental deben expedirse con frecuencia acerca de las diferencias que resultan de una crianza suficientemente buena y aquella que es considerada deficitaria. (Obviamente porque son los que trajinan con los resultados de estos procederes). También es importante saber que las consecuencias que proceden de ciertos estados de carencia no podrán ser revertidas fácilmente. Es decir, el desconocimiento de la impronta que deja en el sujeto sus primeras experiencias vitales no se puede compensar o reparar aún con las mejores intenciones, tal es el caso de una persona encuadrada en la categoría vulnerable somático. En tales casos, los esfuerzos realizados desde los programas psicoeducativos no conducirán a los resultados buscados con el consecuente desaprovechamiento de recursos humanos dispuestos para lograrlo. Podría evitarse la frustración que esto representa para los trabajadores de la salud mental. También es conveniente evaluar el descrédito que conlleva este incumplimiento de las expectativas o pronósticos, a los encargados de la planificación y puesta en marcha de programas de investigación o intervención en el área de la salud mental. De allí la importancia de ahondar en las consecuencias a mediano y largo plazo de ciertas conductas humanas y su particular modo en que deben ser abordarlas.

Por ello, dejar librado al azar los aspectos que permitirán desarrollar este factor puede resultar peligroso. Pocas veces adviene espontáneamente, de allí que lo estudiemos como un fenómeno especial Aunque no está dado al psicólogo, modificar las fuentes del sufrimiento humano, es de suma utilidad que cuente con elementos que facilitarán su tarea en el área de prevención o su intervención clínica, aumentando la eficacia y confiabilidad de su específico ámbito de saber.

\section{ABUSO DEL TÉRMINO "RESILIENCIA"}

Resumiendo, tengo especial interés en recalcar que este trabajo intenta:

a) Sistematizar lo englobado bajo el concepto resiliencia para poder estimularlo donde ya existe y tratar de desarrollarlo donde sea necesario.

b) Buscar ciertas estrategias adecuadas de intervención ante situaciones de adversidad, que ahorre esfuerzo y frustración de las partes intervinientes en el proceso.

c) Evitar la confusión o el giro en la significación del término resiliencia. 
En relación con el último punto, algunos estudiosos se hicieron escuchar acerca del mal uso o abuso que se puede hacer de este concepto. Para algunos conlleva el peligro de ser entendido como sobreadaptación o sometimiento. Otros entienden que ser resiliente significa volver al estado anterior a que sobreviniese la situación traumática, es decir, una pretensión de no cambio. Desde ya que esto es imposible, pues en cuestiones humanas, las experiencias determinan de tal manera al sujeto, que no se recorre dos veces el mismo camino en la misma forma. Ser resiliente, recalco, es poder tolerar y superar la experiencia adversa, pudiendo vivir con ella pero preservando una adecuada calidad de vida, con el menor daño posible.

Con respecto a la sobreadaptación, se le define como una respuesta inconveniente del sujeto frente a un medio que resulta inadecuado, diferenciándola claramente de las conductas adaptativas. En las últimas, el sujeto puede afrontar situaciones conflictivas sin renunciar a su identidad, es decir se preserva, no se aliena.

El sometimiento, como actitud permanente, es una manera posible de encarar la violencia, $\mathrm{y}$ es diferente a todo lo expuesto anteriormente al hablar de factor de resiliencia.

Finalmente, es importante saber que aun en las peores circunstancias, algunas personas encontrarán la manera de sobrevivir y superar lo inefable. Así se evitará la mirada prejuiciosa y desesperanzada del terapeuta, apostando a la creatividad del encuentro terapéutico y del propio sujeto abandonado a sus posibilidades.

Vale la pena recordar que a veces la excelente intención de los profesionales, de extender los límites de un saber para facilitar su quehacer y el de otros científicos, puede ser usado inescrupulosamente, o bien, el contexto puede intentar detractar un elemento útil si es que no puede ser usado con fines espurios. Debemos evitar que algo que nos resulta esclarecedor sea denostado o destruido.

Entiendo que trabajar sobre el concepto de resiliencia aplicado a las ciencias humanas, actualiza cuestiones ya conocidas, articulándolas de manera diferente y sumándole la riqueza que otorga el abordar con seriedad profesional las problemáticas de nuestros consultantes, brindando respuestas a los estragos que produce el actuar irresponsable en materia de lo humano. 